\title{
Case-Based Training of Evidence-Based Clinical Practice in Primary Care and Decreased Mortality in Patients With Coronary Heart Disease
}

\author{
Anna Kiessling, $M D, P b D^{1}$ \\ Moira Lewitt, $M D, P b D^{2}$ \\ Peter Henriksson, MD, PbD \\ 'Department of Clinical Sciences, Karolin- \\ ska Institutet, Division of Cardiovascular \\ Medicine, Danderyd Hospital, Stockholm, \\ Sweden
}

${ }^{2}$ Department of Molecular Medicine \& Surgery, Karolinska Institutet, Stockholm, Sweden
Conflicts of interest: authors report none.

\section{CORRESPONDING AUTHOR}

Anna Kiessling, MD, PhD

Karolinska Institutet

Department of Clinical Sciences

Division of Cardiovascular Medicine

Danderyd Hospital

SE 18288 Stockholm, Sweden

anna.kiessling@ki.se

\begin{abstract}
PURPOSE We investigated the 10-year mortality rates in a trial that tested a casebased intervention in primary care aimed at reducing the gap between evidencebased goals and clinical practice in patients with coronary heart disease (CHD).

METHODS A prospective randomized controlled pragmatic trial was undertaken in a primary care setting. New evidence-based guidelines, with intensified lipidlowering recommendations in CHD, were mailed to all general practitioners in the region and presented at a lecture in 1995. General practitioners $(n=54)$ and patients with CHD $(n=88)$ were assigned according to their primary health care center to 2 balanced groups and randomly allocated to usual care as a control or to an active intervention. General practitioners in the intervention group participated in repeated case-based training during a 2-year period. Patients whose CHD was treated by specialists $(n=167)$ served as an internal specialist comparison group. Altogether, 255 consecutive patients were included. Cox regression analysis was used to detect any survival benefit of the intervention.
\end{abstract}

RESULTS At 10 years, $22 \%$ of the patients in the intervention group had died as compared with $44 \%$ in the control group $(P=.02)$, with a hazard ratio of 0.45 (95\% confidence interval, 0.20-0.95). This difference was mainly due to reduced cardiovascular mortality in the intervention group $(P=.01)$. In addition, the mortality rate of $22 \%$ in the intervention group was comparable to the rate of $23 \%$ seen in patients treated by a specialist.

CONCLUSIONS Use of case-based training to implement evidence-based practice in primary care was associated with decreased mortality at 10 years in patients with CHD.

Ann Fam Med 2011;9:211-218. doi:10.1370/afm.1248.

\section{INTRODUCTION}

I mplementation of evidence-based guidelines in routine primary care is a task of great complexity. A marked gap exists between what is done and what should be done in clinical practice to achieve the target levels in the guidelines. Different barriers to and also some facilitators of implementation have been proposed. ${ }^{1-3}$ Included among proposed barriers are lack of motivation, clinical inertia, and insufficient time. Emphasis on acute rather than preventive tasks and lack of reimbursement may represent further barriers. Known facilitators include audits and feedback, real-time reminders, and academic detailing, whereby prescribing health professionals are trained face to face by experts. ${ }^{4-7}$

It is well known that this gap also exists in secondary prevention among patients with coronary heart disease (CHD) ${ }^{8}$ Reducing the gap 
in this particular context has a potential to save lives. ${ }^{9}$ One way to accomplish this objective and therefore to improve the quality of care could be to apply principles of adult learning. Educational research indicates that methods that activate learners increase knowledge and skills, and can change practice behavior. ${ }^{10}$ Educational intervention studies with patient-related endpoints are scarce, however."1

The above-mentioned barriers to successful implementation of secondary prevention guidelines in primary care seem to have as their common denominator a lack of motivation, knowledge, and beliefs regarding prioritizing time to preventive issues. ${ }^{1-3}$ In theory, it should be possible to overcome such barriers by using a learning method that encourages practitioners to explore and analyze not only the urgent or symptom-driven issues, but also the preventive issues present in the complex decisions of primary care. Case-based training is an activating learning technique aimed particularly at improving skills and attitudes needed in decision making. ${ }^{12}$ We therefore considered it to be a well-suited teaching method in the implementation of guidelines in primary care. We sought to confirm our notion by performing a pragmatic trial, that is, a trial in real clinical practice, which in addition could confirm the effect of lipid lowering in unselected patients with CHD.

We have previously presented the 2-year results for lipid levels in this trial. That is, patients treated by general practitioners in the intervention group had significantly decreased cholesterol levels after 2 years as compared with their counterparts receiving conventional care as a control. ${ }^{13}$ Furthermore, the intervention had a low cost, with the cost of its casebased seminars adding only $2 \%$ to the patients' total lipid-lowering cost. ${ }^{14}$

Here, we report the preplanned 10-year follow-up of mortality in the trial. Our aim was to determine in real clinical practice whether casebased training, intended to optimize management of hyperlipidemia by general practitioners in primary care, improved long-term survival in patients with $\mathrm{CHD}$.

\section{METHODS}

\section{Study Population and Design}

At the start of the study, the primary health care study region in Stockholm County Council, Sweden, had 95,000 inhabitants (Figure 1). Primary care was delivered by 54 general practitioners in 14 primary health care centers. These centers were divided into 2 balanced groups, previously described, ${ }^{13,15}$ that took into account geographic location, rural or urban location, physician density of the primary health care center,

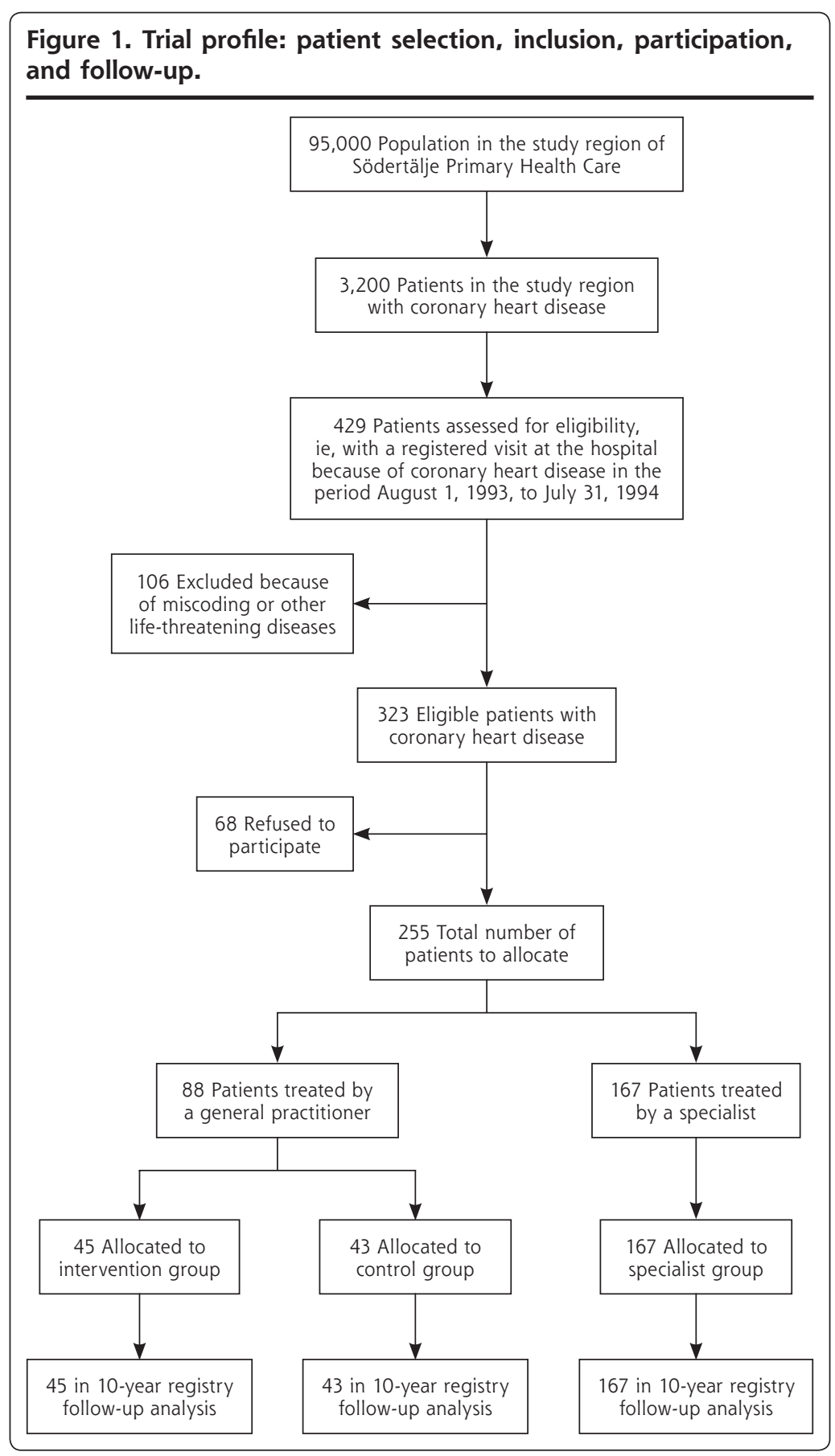


physician relationships, patient numbers, and socioeconomic status of the patient population. A baseline questionnaire given to all general practitioners did not reveal any difference between the 2 groups in perceived knowledge or attitudes regarding risk factors and secondary prevention of CHD. ${ }^{13}$

There were approximately 3,200 patients with $\mathrm{CHD}$ in the study region according to the Public Health Report of Stockholm County Council. ${ }^{16}$ Unfortunately, no register existed that could identify all these patients; however, the local hospital serving all patients in the region with emergency and outpatient specialist care had a register of patients treated as outpatients and inpatients at the hospital. We identified all 429 patients aged younger than 70 years in this register with a diagnosis of CHD, International Classification of Diseases, Ninth Revision (ICD-9) codes 410-414, in the period August 1, 1993, to July 31, 1994. We scrutinized their medical records and thereby identified all 323 patients in the study region who had visited the hospital during this period with a diagnosis of CHD, using predefined criteria: (1) a diagnosis of angina pectoris, either by objective criteria on the basis of coronary angiography or a stress test, or by a clinical assessment on the basis of typical symptoms of angina pectoris during exercise with or without electrocardiographic evidence of possible or definite coronary insufficiency, and (2) a diagnosis of myocardial infarction based either on World Health Organization criteria or on unequivocal electrocardiographic findings. We invited all these patients to participate in the study; 68 patients declined, leaving 255. Recruitment took place between October 1994 and February 1995.

By asking the patients, we identified their responsible general practitioner and primary health care center. On the basis of this information, we divided the patients according to the 2 previously mentioned primary health care center groups. Patients in the 2 groups had similar characteristics, so we had balanced groups of primary health care centers and patients. These 2 groups were subsequently randomly allocated to intervention or control by the toss of a coin. An additional group of patients treated by specialists in cardiology or internal medicine at the hospital or in private practice at baseline were allocated to an internal specialist comparison group.

\section{Guidelines and Educational Intervention}

Local practice guidelines, including new evidence on the effect of lipid lowering in CHD, were formulated immediately after the presentation of a landmark report of the efficacy of lipid lowering in patients with CHD. ${ }^{9}$ The guidelines were presented and distributed at a lecture for all general practitioners and specialists in the study region. A personal letter accompanying the practice guidelines was mailed after the meeting to all relevant physicians in the region.

General practitioners in the intervention group additionally participated in 1 to 2 case seminars per year for 2 years. The case seminars were based on the theoretical framework of case-based training as described by Maufette-Leenders et al. ${ }^{12,17}$ We kept the cases short, and the material presented was simple and well organized. This approach permitted a greater focus on complex conceptual and analytic dimensions. The cases were framed as routine primary care patient encounters or critical situations. Each case had a defined physician who was the decision maker and took place at a defined primary health care center, so that the details of the cases were contextualized and cases were labeled with names. The cases had to be perceived as realistic for the daily practice of the participants and involved a problem or a dilemma without an obvious correct answer. A short summary of such a case has previously been published. ${ }^{15}$

The seminars were conducted in groups of 4 to 7 general practitioners and led by a facilitator, who was a locally well known cardiologist. They began with the presentation of a case. A dialogue between the participants followed and included active problem solving, and a defining and valuing of the pros and cons, and the feasibility of different decisions.

\section{Data Collection}

General practitioner exposure to the study intervention was assessed as attendance rate at the educational seminars, calculated as the mean of the proportion of employed physicians who attended the seminars. An independent organization examined the included patients by repeated questionnaires, blood sampling, and clinical examinations at baseline and during 2 years. This organization was blinded to the patient's study group. The local ethics committee of Karolinska Institutet approved the study.

The Epidemiological Centre of the National Board of Health and Welfare of Sweden assessed patients' vital status after 10 years, ascertaining deaths and their causes from the Swedish Cause of Death Register by use of National Registry Numbers. All Swedish residents have a unique National Registry Number. The Register captures all deaths of individuals registered as Swedish residents, whether or not the death occurred in Sweden. Data were extracted from each patient's inclusion date to the end of 2006.

\section{Statistical Methods and Data Management}

Statistical analysis was performed in the intention-totreat population of patients, and Cox proportional hazards regression analysis was used to compare the study 
groups. To correct for cluster effects, we adjusted the $P$ values of the primary effect variables according to the method of Murray. ${ }^{18}$ We performed a logistic regression analysis on the binary outcome of death and survival to confirm the results of the Cox proportional hazards analysis and included the covariates age, sex, hypertension, smoking, and diabetes. Cumulative incidence and 95\% confidence intervals (CIs) were calculated by the Kaplan-Meier method.

Continuous variables were expressed as mean and standard deviation, and categorical variables were expressed as frequencies, percentages, or both, unless otherwise indicated. The power analysis performed during the initial design of the study showed a power exceeding $80 \%$ after 2 years with respect to the continuous variables of low-density lipoprotein and total cholesterol levels. But a power exceeding $80 \%$ for survival necessitated a follow-up of at least 10 years. We therefore decided to give a primary report on lipid levels after 2 years and a secondary report on survival after 10 years. All analyses were carried out with the statistical software Statistica 9.0 (StatSoft, Tulsa, Oklahoma), and a $P$ value of less than .05 was considered to be significant.

\section{Role of Funding Source}

The Stockholm County Council of Sweden and the Swedish Heart and Lung Foundation funded the trial. These sponsors had no role in the design, management, data collection, analysis, interpretation of data, or writing of the manuscript, or in the decision to submit the results for publication. All authors had full access to the data and had final responsibility for the decision to submit the paper for publication.

\section{RESULTS}

\section{Participant Characteristics}

All initial study patients were included in the 10 -year follow-up, as shown in Figure 1. Selected characteristics of the general practitioners and health care centers are summarized in Table 1 , and patient characteristics are summarized in Table 2 . The 2 primary health care center groups were well balanced regarding characteristics of both patients and physicians, and did not differ at baseline. ${ }^{15}$ Patients in the specialist group did not differ from the primary health care center patients with the exception that they were slightly younger and were more likely to be treated with $\beta$-blockers, lipidlowering drugs, and coronary artery bypass grafting. Physicians' attendance rate at the seminars was $82 \%$.

\section{Outcome of Intervention}

As previously reported, ${ }^{13,14}$ low-density lipoprotein cholesterol levels decreased by $19 \mathrm{mg} / \mathrm{dL}$ (95\% CI, -31 to $-8 \mathrm{mg} / \mathrm{dL}$ ) or $0.5 \mathrm{mmol} / \mathrm{L}(95 \% \mathrm{CI},-0.8$ to -0.2 $\mathrm{mmol} / \mathrm{L}_{;} 9.3 \%$ ) from baseline values in the intervention group, but they remained the same in the control group, with mean changes of $0 \mathrm{mg} / \mathrm{dL}(95 \% \mathrm{CI},-8$ to $8 \mathrm{mg} / \mathrm{dL}$ ) and $0 \mathrm{mmol} / \mathrm{L}(95 \% \mathrm{CI},-0.2$ to $0.2 \mathrm{mmol} / \mathrm{L}$; $0.7 \%)$. Furthermore, use of statins expressed in defined daily doses ${ }^{19}$ increased by 0.2 such doses (95\% CI, 0.1 to $0.3 ; P=.04)$ between baseline and 2 years in the intervention group, but did not change in the control group (95\% $\mathrm{CI},-0.1$ to $0.1 ; P$ not significant).

After 10 years, $22 \%$ (10 of 45 ) of the patients in the intervention group had died, as compared with $44 \%$ (19 of 43) in the control group (Table 3 and Figure 2; $P=.02$ ). The difference remained significant after inclusion of the covariates age, sex, hypertension, smoking, and diabetes, and use of logistic regression analysis. The hazard ratio for death was 0.45 (95\% CI, 0.20-0.95) when case-based training was used to assist implementation of evidence-based care, compared with the control condition. The mortality rate of $22 \%$ in the intervention group was comparable to the rate of 23\% (39 of 167 patients) in the group treated by a specialist.

The distribution of the causes of death is given in Table 3. The difference in the rate of all-cause mortality was driven by a difference in the rate of cardio-

\begin{tabular}{|c|c|c|}
\hline Characteristic & Intervention & Control \\
\hline General practitioners, No. ${ }^{a}$ & 26 & 28 \\
\hline Age, mean (SD), y & $47.0(6.3)$ & $46.4(4.8)$ \\
\hline Women, No. (\%) & $9(35)$ & $9(32)$ \\
\hline \multirow{2}{*}{$\begin{array}{l}\text { Patients per physician, median } \\
\text { (range), No. }\end{array}$} & $1(0-4)$ & $1(0-5)$ \\
\hline & No. & No. \\
\hline Primary health care centers & 7 & 7 \\
\hline \multicolumn{3}{|l|}{ Physicians per center } \\
\hline $1-3$ & 3 & 3 \\
\hline $4-5$ & 3 & 2 \\
\hline$\geq 6$ & 1 & 2 \\
\hline \multicolumn{3}{|l|}{ Inhabitants per center } \\
\hline$\leq 4,999$ & 2 & 2 \\
\hline $5,000-9,999$ & 2 & 3 \\
\hline$\geq 10,000$ & 3 & 2 \\
\hline \multicolumn{3}{|l|}{ Mean income per capitab } \\
\hline$\leq 149$ kSEK & 1 & 1 \\
\hline 150-199 kSEK & 5 & 4 \\
\hline$\geq 200$ kSEK & 1 & 2 \\
\hline \multicolumn{3}{|l|}{ Location } \\
\hline Urban only & 5 & 5 \\
\hline Mixed urban and rural & 2 & 2 \\
\hline
\end{tabular}


vascular disease mortality, which was half as high in the intervention group as in the control group (16\% vs $33 \%, P=.01$ ). This difference, in turn, was largely driven by a reduction in the rate of deaths from $\mathrm{CHD}$ $(11 \%$ vs $28 \%, P=.02)$.

\section{DISCUSSION}

Our study's findings suggest that case-based training in the context of contemporary clinical practice is effective not only in decreasing hyperlipidemia among patients with CHD, but also in decreasing their mor-

\section{Table 2. Baseline Characteristics of Patients}

\begin{tabular}{|c|c|c|c|c|c|}
\hline \multirow[b]{2}{*}{ Characteristic } & \multirow[b]{2}{*}{$\begin{array}{l}\text { Total } \\
(\mathbf{N}=255)\end{array}$} & \multicolumn{3}{|c|}{ Group } & \multirow[b]{2}{*}{$\begin{array}{l}\text { Specialist } \\
\text { ( } n=167)\end{array}$} \\
\hline & & $\begin{array}{l}\text { Intervention } \\
(n=45)\end{array}$ & $\begin{array}{l}\text { Control } \\
(n=43)\end{array}$ & $\begin{array}{c}P \\
\text { Value }\end{array}$ & \\
\hline Age, mean (SD), y & $60.1(7.5)$ & $62.6(6.1)$ & $62.3(7.4)$ & .93 & $59.0(7.6)$ \\
\hline Women, No. (\%) & $57(22)$ & $8(18)$ & $5(12)$ & .55 & $44(26)$ \\
\hline \multicolumn{6}{|l|}{ Comorbidities, No. (\%) } \\
\hline Diabetes & $37(15)$ & $5(11)$ & $6(14)$ & .76 & $26(16)$ \\
\hline Hypertension & $67(26)$ & $16(36)$ & $10(23)$ & .25 & $41(25)$ \\
\hline Other & $71(28)$ & $11(24)$ & $12(28)$ & .81 & $48(29)$ \\
\hline Current smoker, No. (\%) & $61(24)$ & $10(23)$ & $9(21)$ & .89 & $42(25)$ \\
\hline BMI, mean (SD), kg/m² & $28.0(4.2)$ & $28.1(5.5)$ & $27.2(3.4)$ & .34 & $28.1(3.9)$ \\
\hline \multicolumn{6}{|l|}{$\mathrm{BP}$, mean (SD), $\mathrm{mm} \mathrm{Hg}$} \\
\hline Systolic & $139(20)$ & $142(19)$ & $139(20)$ & .59 & $138(21)$ \\
\hline Diastolic & $84(9)$ & $84(10)$ & $85(8)$ & .70 & $84(9)$ \\
\hline \multicolumn{6}{|l|}{$\begin{array}{l}\text { Lipid levels, mean (SD), } \\
\mathrm{mg} / \mathrm{dL}^{\mathrm{a}}\end{array}$} \\
\hline Total cholesterol & $247(43)$ & 244 (39) & $240(43)$ & - & $247(46)$ \\
\hline Triglycerides & $186(97)$ & $186(106)$ & $186(89)$ & - & $186(97)$ \\
\hline HDL cholesterol & $46(12)$ & $46(15)$ & $43(12)$ & - & $46(12)$ \\
\hline LDL cholesterol & $162(39)$ & $162(31)$ & $159(39)$ & - & $166(39)$ \\
\hline \multicolumn{6}{|l|}{ Medications, No. (\%) } \\
\hline Acetyl salicylic acid & $205(80)$ & $38^{b}(86)$ & $33(77)$ & .28 & $134(80)$ \\
\hline$\beta$-blocker & $166(65)$ & $25(56)$ & $21(49)$ & .50 & $119(71)$ \\
\hline Lipid-lowering drugs & 49 (19) & $6^{b}(14)$ & $3(7)$ & .48 & $40(24)$ \\
\hline $\begin{array}{l}\text { Duration of CHD, } \\
\text { mean (SD), y }\end{array}$ & $6.0(5.6)$ & $5.6(5.8)$ & $6.2(5.9)$ & .62 & $6.0(5.4)$ \\
\hline \multicolumn{6}{|l|}{ History, No. (\%) } \\
\hline $\mathrm{Ml}$ & $167(65)$ & $29(64)$ & $23(53)$ & .39 & $115(69)$ \\
\hline CABG & $95(37)$ & $12(27)$ & $13(30)$ & .81 & $70(42)$ \\
\hline $\mathrm{PCl}$ & $29(11)$ & $2(4)$ & $3(7)$ & .67 & $24(14)$ \\
\hline \multicolumn{6}{|l|}{ CCS class, No. (\%) } \\
\hline $0-1$ & $147(59)$ & $25(60)$ & $29(69)$ & .49 & $93(56)$ \\
\hline $2-4$ & $103(41)$ & $17(40)$ & $13(31)$ & & $73(44)$ \\
\hline \multicolumn{6}{|c|}{$\begin{array}{l}\mathrm{BMI}=\text { body mass index; } \mathrm{BP}=\text { blood pressure; } \mathrm{CABG}=\text { coronary artery bypass grafting; } \mathrm{CCS}=\mathrm{Canadian} \text { Car- } \\
\text { diovascular Society classification system of current angina pectoris symptoms; } \mathrm{CHD}=\text { coronary heart disease; } \\
\mathrm{HDL}=\text { high-density lipoprotein; } \mathrm{LDL}=\text { low-density lipoprotein; } \mathrm{MI}=\text { myocardial infarction; } \mathrm{PCI}=\text { percutaneous } \\
\text { coronary intervention. }\end{array}$} \\
\hline \multicolumn{6}{|c|}{$\begin{array}{l}\text { Notes: Patient group reflects the group to which the patient's treating physician was assigned. Specialist denotes } \\
\text { the group of patients treated by a specialist in cardiology or internal medicine. }\end{array}$} \\
\hline \multicolumn{6}{|c|}{$\begin{array}{l}\text { a Triglyceride values in millimoles per liter were converted to milligrams per deciliter by multiplying by } 88.57 \text {. } \\
\text { Other cholesterol values were converted to milligrams per deciliter by multiplying by } 38.67 \text {. } \\
\text { b Based on } 44 \text { patients having data for these measures. } \\
\text { ' Based on } 250 \text { patients having data for this measure. }\end{array}$} \\
\hline
\end{tabular}

tality. We performed a randomized controlled pragmatic trial aimed at changing the clinical practice of physicians in primary care toward greater adherence to new comprehensive guidelines on evidence-based care. We used case-based training for physicians and assessed its effectiveness as survival benefit for their patients. After 10 years, total and cardiovascular mortality were lower in the patients treated by the trained general practitioners.

Successful management of hyperlipidemia is likely to be the pivotal mechanism underlying the observed reduction in mortality. This supposition is supported by our 2 -year finding that the use of lipid-lowering drugs had increased from baseline and was higher in the patients in the intervention group vs those in the control group. ${ }^{14}$ Furthermore, these patients' cholesterol levels had decreased..$^{13} \mathrm{We}$ propose that the initial critical mechanism explaining this finding was a change in prescribing practice by their treating physicians. Our findings suggest that active participation of physicians in 3 or 4 case-based seminars lasting 1 hour each during a 2-year period at their primary health care centers was in this context enough to change this critical aspect of clinical practice.

Conducting interventional studies in real clinical practice, that is, pragmatic trials, is an important task, but also a complex one. Furthermore, patients in real clinical practice are reported to have a worse prognosis than those who are recruited to and included in clinical trials. ${ }^{20,21}$ This differential might hypothetically be explained by the inclusion and exclusion criteria of conventional clinical trials.

A recent review suggests that interactive educational strategies are more effective than noninteractive ones, and that multiple exposures to educational activities seem to be more effective than a single 
exposure. ${ }^{22}$ Our findings support these concepts. The minor time required for our intervention means that a lot of different diseases could be covered during the limited time available for continuing medical education activities. An additional powerful advantage of this educational strategy is its low cost. ${ }^{14}$

Table 3. Mortality and Cause of Death

\begin{tabular}{|c|c|c|c|c|c|}
\hline \multirow[b]{2}{*}{ Cause of Death } & \multirow[b]{2}{*}{$\begin{array}{c}\text { Total } \\
(\mathrm{N}=255) \\
\text { No. }(\%)\end{array}$} & \multicolumn{3}{|c|}{ Group } & \multirow[b]{2}{*}{$\begin{array}{c}\text { Specialis } \\
(n=167) \\
\text { No. }(\%)\end{array}$} \\
\hline & & $\begin{array}{c}\text { Intervention } \\
(n=45) \\
\text { No. }(\%)\end{array}$ & $\begin{array}{l}\text { Control } \\
(n=43) \\
\text { No. }(\%)\end{array}$ & $\begin{array}{c}P \\
\text { Value }\end{array}$ & \\
\hline All deaths & $68(27)$ & $10(22)$ & $19(44)$ & .02 & $39(23)$ \\
\hline Cardiovascular deaths & $43(17)$ & $7(16)$ & $14(33)$ & .01 & $22(13)$ \\
\hline Coronary heart disease & $36(14)$ & $5(11)$ & $12(28)$ & .02 & $19(11)$ \\
\hline Other vascular cause & $7(3)$ & $2(4)$ & $2(5)$ & .37 & $3(2)$ \\
\hline $\begin{array}{l}\text { Noncardiovascular } \\
\text { deaths }\end{array}$ & $25(10)$ & $3(7)$ & $5(12)$ & .68 & $17(10)$ \\
\hline Neoplasia & $15(6)$ & $2(4)$ & $2(5)$ & .93 & $11(7)$ \\
\hline Other & $10(4)$ & $1(2)$ & $3(7)$ & .40 & $6(4)$ \\
\hline
\end{tabular}

Notes: Cox regression analysis was used to compare the groups. $P$ values are adjusted for group-randomized trials according to the method of Murray..$^{18}$ The intraclass correlation coefficient (ICC) was 0.12 for all deaths, 0.14 for coronary heart disease deaths, and 0.14 for cardiovascular deaths. Results were confirmed by logistic regression analysis and the inclusion of the covariates age, sex, hypertension, smoking, and diabetes.
The focus of the dialogues at the primary health care centers was not on knowledge of evidence per se, but on how and when to apply this evidence in the physicians' decisions in their own everyday work. We expected that the dialogues should focus on how to reorganize their handling of patients with CHD.

A review evaluating effects of organizational change in the area of cancer screening in primary care practices has recently been published. ${ }^{23}$ It recommends that organizational change be implemented in a way that is tailored to the primary care practice. It is well recognized that the framing of a decision has great implications on the resulting choice. ${ }^{24}$ Another possible contributing factor to the effect was the fact that the case-based training sessions took place at the practitioners' own primary health care centers, that is, in the same con-

\section{Figure 2. Cumulative proportion of deceased patients in the intervention and control groups treated} by general practitioners, and in the group treated by specialists.

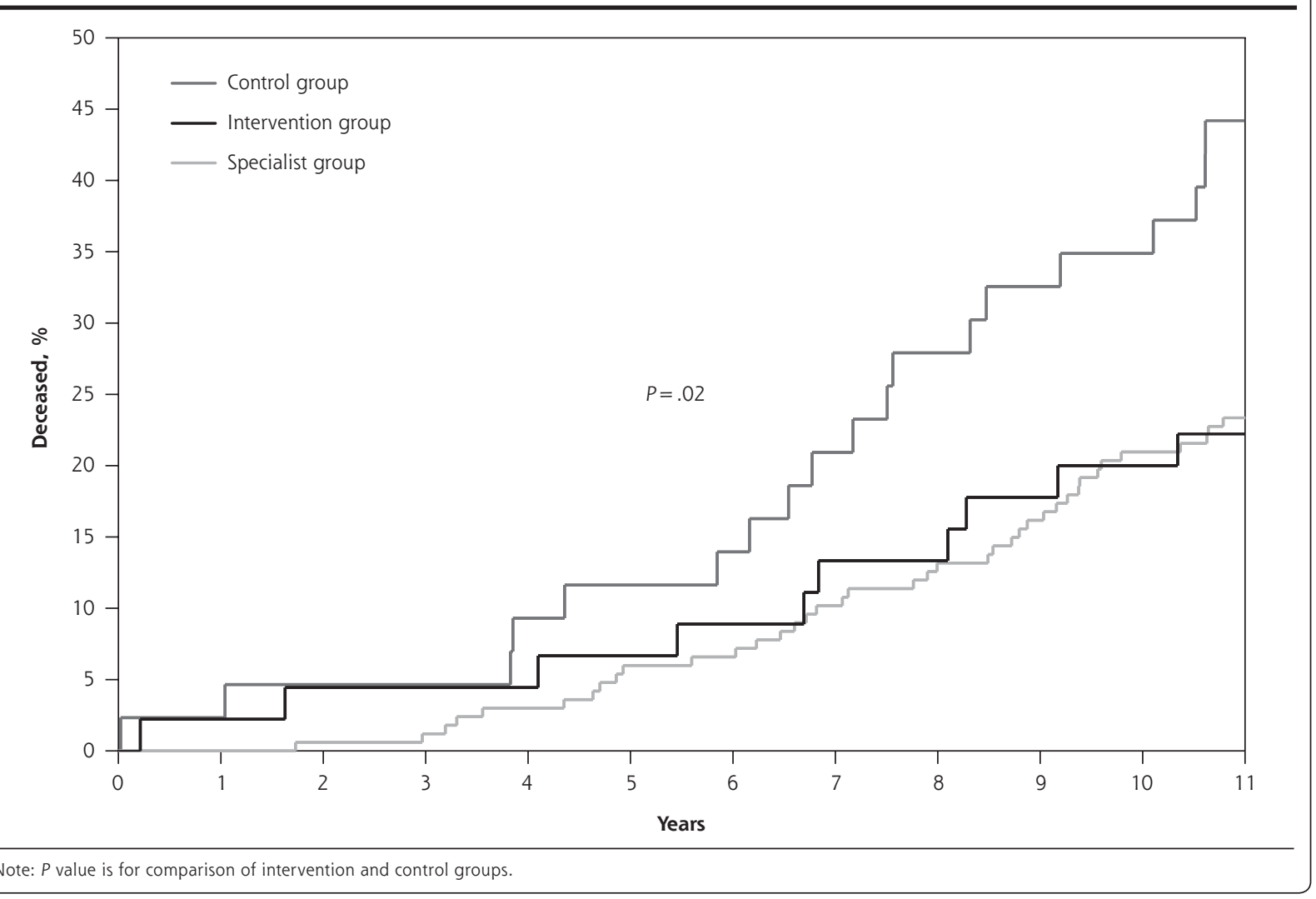


text wherein the behavior change was desired to occur. In this respect, outreach visits and academic detailing have also been shown to be effective. ${ }^{7}$

Besides the guideline content, the case discussions covered other factors that are important for patient management decisions, for example, working conditions, family situation, lifestyle, economic constraints, and social and cultural circumstances, not only of the patient, but also of the physician. Hypothetically, the most important components of the decision analyses in the case seminars were of abstract nature and included attitudes, beliefs, emotions, motivation, knowledge, expectations, and ethical aspects of both the patient and the physician. Subsequently, urgency and timingthat is, when - and aspects of responsibility - that is, who-were discussed and analyzed. The discussions all concluded with a consensus of strategies and action plans regarding how to handle similar cases in the future. We could in addition hypothesize that the casebased dialogues helped the physicians to switch focus from reactive solving of acute patient symptoms to a more proactive strategy for patients at risk, regardless of the presence of symptoms.

Our study was limited by the small number of patients, which might have resulted in unequal distribution of confounders between the intervention and control groups. In addition, we included only patients who had a hospital visit for CHD in the year before study entry. The study was randomized, with 2 balanced cohorts of physicians and patients, however, and had a reasonable power at its initiation. We further tested the robustness of the results by logistic regression analysis and by inclusion of covariates concerning well-known risk factors. Those adjustments did not change the significance of the results. We hypothesize that the change in behavior among participating physicians was the true critical mechanism initiating the decrease in mortality seen in the intervention group. As previously noted, this was a pragmatic trial. In all such trials, it is impossible per se to control for all expected and unexpected confounders. In spite of this limitation, we are convinced that a pragmatic study design is the most appropriate method to evaluate interventions aimed at teaching general practitioners how to implement guidelines in their everyday work. These physicians are generalists and deal with a broad spectrum of diseases. The demand for effective strategies for continuing medical education in primary care aimed at quality improvement is therefore huge. ${ }^{25}$ It is probably not possible to draw broad generalizations from a single-center study with a small sample size. The results are nonetheless promising.

To conclude, we found that case-based training with a trained facilitator, aimed at promoting imple- mentation of evidence-based care in general practice, increased the use of lipid-lowering drugs, decreased cholesterol levels, and was associated with reduced mortality in a cohort of patients with CHD. We strongly recommend that these effects of case-based training be tested in other areas of clinical practice.

To read or post commentaries in response to this article, see it online at http://www.annfammed.org/cgi/content/full/9/3/211.

Key words: Coronary artery disease; quantitative methods; randomized clinical trial; primary care issues; clinical practice guidelines; practicebased research

Submitted June 27, 2010; submitted, revised, December 28, 2010; accepted January 13, 2011.

Versions of this study were presented at the American College of Cardiology's 58th Annual Scientific Session, March 28 to 31, 2009, in Orlando, Florida, and at the European Society of Cardiology Annual Congress, August 29 to September 2, 2009, in Barcelona, Spain.

Funding support: This study was supported by grants from the Stockholm County Council and the Swedish Heart and Lung Foundation.

Acknowledgments: We thank Katarina Patzelt-Brandt for invaluable support in performing all patient interviews and data collections.

\section{References}

1. Hickling J, Rogers S, Nazareth I. Barriers to detecting and treating hypercholesterolaemia in patients with ischaemic heart disease: primary care perceptions. Br J Gen Pract. 2005;55(516):534-538.

2. Majumdar SR, McAlister FA, Furberg CD. From knowledge to practice in chronic cardiovascular disease: a long and winding road. J Am Coll Cardiol. 2004;43(10):1738-1742.

3. Hobbs FD, Erhardt L. Acceptance of guideline recommendations and perceived implementation of coronary heart disease prevention among primary care physicians in five European countries: the Reassessing European Attitudes about Cardiovascular Treatment (REACT) survey. Fam Pract. 2002;19(6):596-604.

4. Majumdar SR, Tsuyuki RT, McAlister FA. Impact of opinion leaderendorsed evidence summaries on the quality of prescribing for patients with cardiovascular disease: a randomized controlled trial. Am Heart J. 2007;153(1):22.e1-e8.

5. Davis D, O'Brien MA, Freemantle N, Wolf FM, Mazmanian P, Taylor-Vaisey A. Impact of formal continuing medical education: do conferences, workshops, rounds, and other traditional continuing education activities change physician behavior or health care outcomes? JAMA. 1999;282(9):867-874

6. O'Brien MA, Rogers S, Jamtvedt G, et al. Educational outreach visits: effects on professional practice and health care outcomes. Cochrane Database Syst Rev. 2007;(4):CD000409.

7. Doumit G, Gattellari M, Grimshaw J, O’Brien MA. Local opinion leaders: effects on professional practice and health care outcomes. Cochrane Database Syst Rev. 2007;(1):CD000125.

8. Kotseva K, Wood D, De Backer G, De Bacquer D, Pyörälä K, Keil U; EUROASPIRE Study Group. Cardiovascular prevention guidelines in daily practice: a comparison of EUROASPIRE I, II, and III surveys in eight European countries. Lancet. 2009;373(9667):929-940.

9. Randomised trial of cholesterol lowering in 4444 patients with coronary heart disease: the Scandinavian Simvastatin Survival Study (4S). Lancet. 1994;344(8934):1383-1389. 
10. Thomson O'Brien MA, Freemantle N, Oxman AD, Wolf F, Davis DA, Herrin J. Continuing education meetings and workshops: effects on professional practice and health care outcomes. Cochrane Database Syst Rev. 2001;(2):CD003030.

11. Hutchinson L. Evaluating and researching the effectiveness of educational interventions. BMJ. 1999;318(7193):1267-1269.

12. Mauffette-Leenders LA, Erskine JA, Leenders MR. Learning With Cases. London, ON, Canada: Richard Ivey School of Business, University of Western Ontario; 1997.

13. Kiessling A, Henriksson P. Efficacy of case method learning in general practice for secondary prevention in patients with coronary artery disease: randomised controlled study. BMJ. 2002;325(7369):877-880.

14. Kiessling A, Zethraeus N, Henriksson P. Cost of lipid lowering in patients with coronary artery disease by case method learning. Int J Technol Assess Health Care. 2005;21(2):180-186.

15. Kiessling A, Henriksson P. Efficacy of case method learning in general practice for secondary prevention in patients with coronary artery disease: randomised controlled study. BM 2002;325(7369):877-880. Additional tables and other details are available from: http://www.bmj.com/cgi/content/full/325/7369/877/ DC1. Accessed July 3, 2010.

16. Burström B, Diderichsen F, eds. Public Health Report of Stockholm County Council 1999. Public Health Reports. 1999:1-115. ISSN: 0284-4036.

17. Leenders MR, Mauffette-Leenders LA, Erskine JA. Writing Cases. 4th ed. London, ON, Canada: Research and Publications Division School of Business Administration, University of Western Ontario; 2001.
18. Murray DM. Design and Analysis of Group-Randomized Trials. New York, New York: Oxford University Press; 1998.

19. WHO Collaborating Centre for Drug Statistics Methodology, Norwegian Institute of Public Health. Guidelines for ATC Classification and DDD Assignment 2006. Oslo, Norway: WHO Collaborating Centre for Drug Statistics Methodology; 2006.

20. Steg PG, López-Sendón J, Lopez de Sa E, et al; GRACE Investigators. External validity of clinical trials in acute myocardial infarction. Arch Intern Med. 2007;167(1):68-73.

21. Rothwell PM. External validity of randomised controlled trials: "To whom do the results of this trial apply?" Lancet. 2005;365(9453): 82-93.

22. Marinopoulos SS, Dorman T, Ratanawongsa N, et al. Effectiveness of continuing medical education. Evid Rep Technol Assess (Full Rep). 2007;Jan(149):1-69.

23. Arroyave AM, Penaranda EK, Lewis CL. Organizational change: a way to increase colon, breast and cervical cancer screening in primary care practices. J Community Health. 2011;36(2):281-288.

24. Tversky A, Kahneman D. The framing of decisions and the psychology of choice. Science. 1981;211(4481):453-458

25. Slawson DC, Shaughnessy AF. Teaching evidence-based medicine: should we be teaching information management instead? Acad Med. 2005;80(7):685-689. 